\title{
Characterizing Drought and Flood Events over the Yangtze River Basin Using the HUST-Grace2016 Solution and Ancillary Data
}

\author{
Hao Zhou ${ }^{1,2, *}$, Zhicai Luo ${ }^{1,3}$, Natthachet Tangdamrongsub ${ }^{4}$ (D), Lunche Wang ${ }^{5}$ (D), Lijie He ${ }^{6}$, \\ Chuang $\mathrm{Xu}{ }^{1}$ and Qiong $\mathrm{Li}^{1}$ \\ 1 MOE Key Laboratory of Fundamental Physical Quantities Measurement, \\ Hubei Key Laboratory of Gravitation and Quantum Physics, Institute of Geophysics, \\ School of Physics, Huazhong University of Science and Technology, Wuhan 430074, China; \\ zcluo@hust.edu.cn (Z.L.); chuangxu@hust.edu.cn (C.X.); qiongli@hust.edu.cn (Q.L.) \\ 2 State Key Laboratory of Geodesy and Earth's Dynamics, Institute of Geodesy and Geophysics, \\ Chinese Academy of Sciences, Wuhan 430077, China \\ 3 Collaborative Innovation Center of Geospatial Technology, Wuhan University, Wuhan 430079, China \\ 4 School of Engineering, University of Newcastle, Callaghan 2308, New South Wales, Australia; \\ natthachet.tangdamrongsub@newcastle.edu.au \\ 5 Department of Geography, School of Earth Sciences, China University of Geosciences, Wuhan 430074, China; \\ wang@cug.edu.cn \\ 6 School of Resource and Environmental Science, Wuhan University, Wuhan 430079, China; \\ lijiehe@whu.edu.cn \\ * Correspondence: zhouh@hust.edu.cn; Tel.: +86-155-2781-4858
}

Received: 1 September 2017; Accepted: 25 October 2017; Published: 27 October 2017

\begin{abstract}
Accurate terrestrial water storage (TWS) estimation is important to evaluate the situation of the water resources over the Yangtze River Basin (YRB). This study exploits the TWS observation from the new temporal gravity field model, HUST-Grace2016 (Huazhong University of Science and Technology), which is developed by a new low-frequency noise processing strategy. A novel GRACE (Gravity Recovery and Climate Experiment) post-processing approach is proposed to enhance the quality of the TWS estimate, and the improved TWS is used to characterize the drought and flood events over the YRB. The HUST-Grace2016-derived TWS presents good agreement with the CSR (Center for Space Research) mascon solution as well as the PCR-GLOBWB (PCRaster Global Water Balance) hydrological model. Particularly, our solution provides remarkable performance in identifying the extreme climate events e.g., flood and drought over the YRB and its sub-basins. The comparison between GRACE-derived TWS variations and the MODIS-derived (Moderate Resolution Imaging Spectroradiometer) inundated area variations is then conducted. The analysis demonstrates that the terrestrial reflectance data can provide an alternative way of cross-comparing and validating TWS information in Poyang Lake and Dongting Lake, with a correlation coefficient of 0.77 and 0.70 , respectively. In contrast, the correlation is only 0.10 for Tai Lake, indicating the limitation of cross-comparison between MODIS and GRACE data. In addition, for the first time, the NCEP/NCAR (National Centers for Environmental Prediction/National Center for Atmospheric Research) vertical velocity data is incorporated with GRACE TWS in the exploration of the climate-induced hydrological activities. The good agreement between non-seasonal NCEP/NCAR vertical velocities and non-seasonal GRACE TWSs is found in flood years (2005, 2010, 2012 and 2016) and drought years (2006, 2011 and 2013). The evidence shown in this study may contribute to the analysis of the mechanism of climate impacts on the YRB.
\end{abstract}

Keywords: Yangtze River Basin; GRACE; PCR-GLOBWB; MODIS; NCEP/NCAR; TWS; groundwater; forward-modeling; vertical velocity; drought and flood events 


\section{Introduction}

The Yangtze River Basin (YRB), with a total drainage area of approximately 1.8 million $\mathrm{km}^{2}$, serves as the primary fresh water resource for more than 400 million people in China. Compounded by climate variability, the extreme and frequent hydrological activities, including floods and droughts, have caused numerous civilian casualties and enormous property losses [1]. To mitigate these damages, the long-term monitoring of the water resource variations over YRB and its sub-basins is definitely and urgently needed. Therefore, multi-remote-sensing observations have been applied. Using these observations, the comprehensive assessment of terrestrial water storage (TWS) variations over the YRB and its sub-basins may yield valuable insight into hydrological activities during 2003-2016.

Since 2002, TWS variations derived from the Gravity Recovery and Climate Experiment (GRACE) mission have been widely used to identify the extreme hydrological activities over large-scale regions. Examples include the YRB [2,3], the Amazon River Basin [4,5], the Nile River Basin [6], the Sichuan Basin [7], the southwest of China [8], etc. In these studies, the products in the form of spherical harmonic coefficients (SHCs) were commonly exploited. For instance, the Release 05 (RL05) models provided by Center for Space Research (CSR) [9], GeoForschungsZentrum (GFZ) [10] and the Jet Propulsion Laboratory (JPL) [11]. Recently, a new temporal gravity field model HUST-Grace2016 was developed using a modified dynamic approach [12]. In this study, compared with the ensemble model developed using three RL05 models $[13,14]$, the performance of our independently developed model HUST-Grace2016 was assessed. It was then used to estimate the TWSs over the YRB as well as its sub-basins.

Apart from the GRACE models, the hydrological model PCRaster Global Water Balance (PCR-GLOBWB) was also applied to estimate TWS variations [3,15-17]. Compared with the commonly used hydrological model Global Land Data Assimilation System (GLDAS) [18], the PCR-GLOBWB model constructs TWS with soil moisture, groundwater and surface water. Therefore, for the first time, it was used to estimate the contribution of each water component over the YRB as well as its sub-basins. In addition, as an independent source, it was also used to evaluate the performance of GRACE-derived TWS variations.

Furthermore, the MODIS-derived (Moderate Resolution Imaging Spectroradiometer) inundated area variations have been used to identify the floods over some freshwater lakes [16,19]. Specially, Tangdamrongsub et al. [16] conducted a comparison between GRACE-derived TWS variations and MODIS-derived inundated area variations. For the first time, the results demonstrated that MODIS surface reflectance observations showed great potential in estimating the total TWS variations over the Tonlé Sap basin. The three largest freshwater lakes of China are located in the YRB, with different geographic features. Can MODIS data be used to cross-compare and validate the TWS variations over these regions? What is the application scope of MODIS-derived inundated areas for TWS variation cross-comparison and validation? This study also tried to give the corresponding answers and explanations.

In past studies, comparisons between GRACE-derived TWS and meteorological indices have been conducted $[2,7,20-25]$. These meteorological indices were mainly related to sea surface temperature, which were mainly derived from the NCEP/NCAR (National Centers for Environmental Prediction/National Center for Atmospheric Research) reanalysis dataset [26]. They were proven to be helpful to build the teleconnections between extreme hydrological activities and meteorological parameters. In this study, incorporated with our own GRACE model, the vertical velocity data over the YRB was used to build a direct connection with GRACE-derived TWS. This may be helpful in investigating climate-induced hydrological activities over the YRB.

The main objectives of this study are summarized as follows: (1) assessing the performance of our independently developed GRACE model, HUST-Grace2016; (2) characterizing the hydrological activities of the YRB with a combination of GRACE-derived and hydrological-model-derived TWSs, as well as MODIS-derived inundated areas; (3) trying to figure out the inducement of hydrological activities over the YRB with the incorporation of GRACE and NCEP/NCAR data. 


\section{Study Region and Data Processing}

\subsection{Study Region}

The YRB can be divided into 11 sub basins (Figure 1). Seven of them are located along the tributaries of the Yangtze River: Jinsha River Basin, Minjiang River Basin, Jialing River Basin, Hanjiang River Basin, Wujiang River Basin, Dongting Lake Basin and Poyang Lake Basin. The other four sub-basins are located along the mainstream of Yangtze River: Upstream Basin, Midstream Basin, Downstream Basin and Delta Plain Basin. For clarity, UMDD is used below to represent the group of these four sub-basins in this study. The three largest freshwater lakes in China are also located in the YRB: Poyang Lake, Dongting Lake and Tai Lake. MODIS observations were used to assess their inundated area variations in Section 3.2.

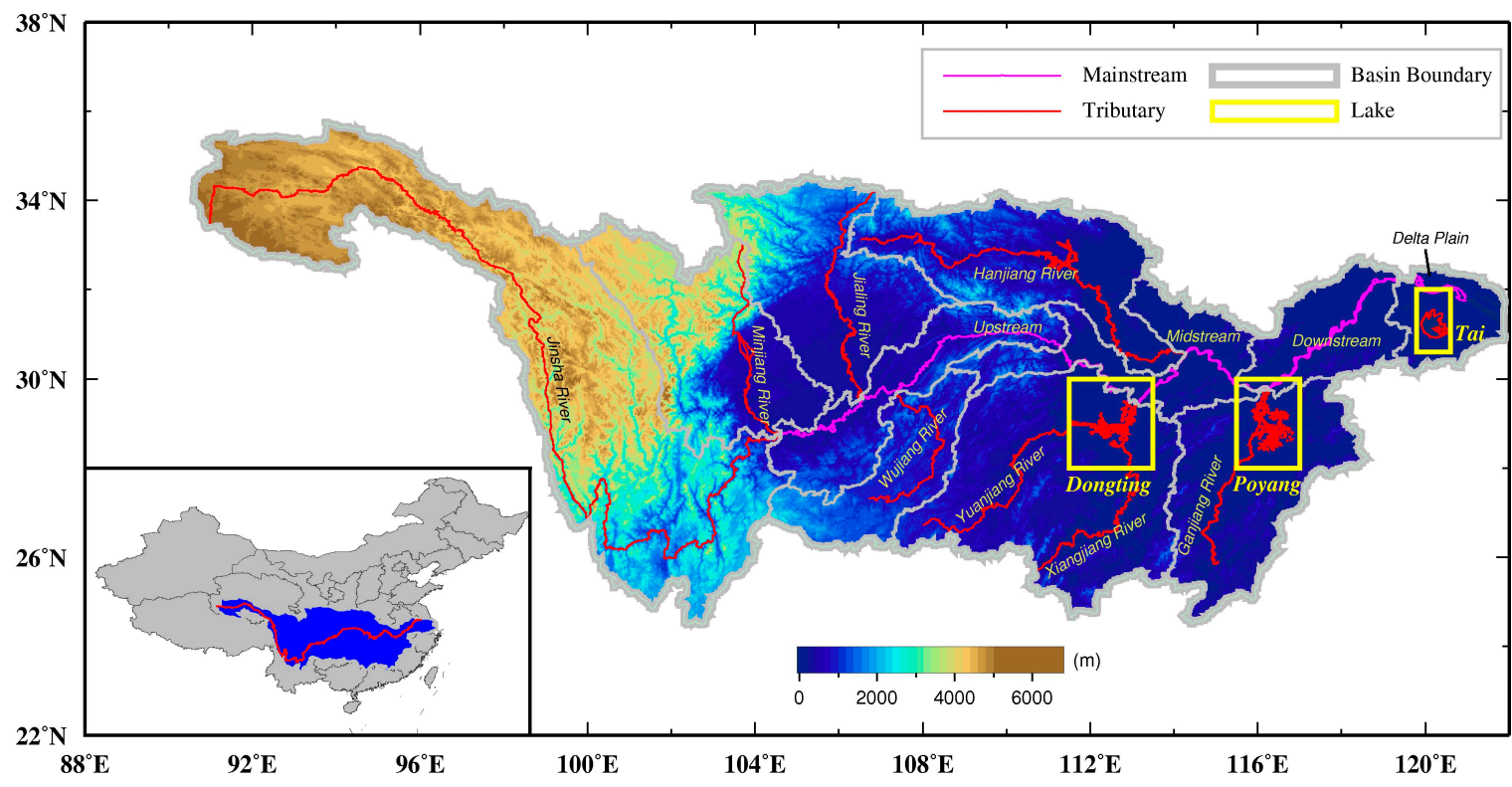

Figure 1. The location of the Yangtze River Basin over China.

The YRB has a subtropical monsoon climate, with an annual precipitation of approximately $1067 \mathrm{~mm}$. It is characterized by a rainy period between April and September, and a dry period between October and March. Due to the vast territory, complicated topography and typical monsoon climate, the spatial and temporal distributions of annual precipitation and rainstorms are heterogeneous over the YRB. Therefore, in addition to the whole YRB, the flood and drought events that occurred in its sub-basins were also investigated in this study. For clarity, the four sub-basins (Jinsha River Basin, Minjiang River Basin, Jialing River Basin and Wujiang River Basin), located in the west YRB, are called WYRB. The remaining sub basins, which locate at the east of the YRB, are called EYRB in this study.

\subsection{Data and Data Processing}

\subsubsection{GRACE Data}

The new temporal gravity model HUST-Grace2016 (Huazhong University of Science and Technology, Wuhan, Hubei, China), which was developed by a new low-frequency noise processing strategy, was used to compute TWS variations over the YRB. The processing strategy has been explicitly described in Zhou et al. [12]. The new model has been uploaded to the website of International Centre for Global Earth Models (ICGEM, http:/ /icgem.gfz-potsdam.de/home). To validate HUST-Grace2016, the RL05 models provided by the CSR, GFZ and JPL were exploited. Meanwhile, the ensemble model, which was developed using three RL05 models, was also used to assess the performance of our new 
HUST-Grace2016 model $[13,14]$. These models come in the form of SHCs up to degree and order 60 , corresponding to a spatial resolution of about $330 \mathrm{~km}$. Since the low degree coefficients cannot be determined reliably by the GRACE mission, they were treated in the following ways: degree-1 coefficients were replaced by the values provided by Swenson et al. [27], and degree-2 zonal time series were replaced by a set of satellite laser ranging data [28]. Two different filters were applied to alleviate the effects of the high-frequency errors inherent to the GRACE temporal gravity field models: a Gaussian filter with a radius of $300 \mathrm{~km}$ [29], and a de-correlation filter from order six with a three order polynomial (P3M6) [30]. These filters would cause signal leak into adjacent areas, called leakage error. To mitigate these leakage errors, the forward-modeling method was used.

The forward-modeling method was implemented as follows: (1) the input was the 'filtered reference TWS', which was computed by applying a $300 \mathrm{~km}$ Gaussian filter and a P3M6 de-correlation filter; it was then set as 'candidate TWS' in the first iteration; (2) the 'candidate TWS' was assigned uniformly over the ocean. It was the opposite value of the mean TWS over land. After that, the 'candidate TWS' was converted to SHCs; (3) after applying a $300 \mathrm{~km}$ Gaussian filter, the 'filtered candidate TWS' was computed; (4) the 'TWS increment' was computed as the difference between the 'filtered reference TWS' and 'filtered candidate TWS'; (5) if the 'TWS increment' of each grid was smaller than the threshold $(0.5 \mathrm{~cm}$ in this study), stopped at this iteration; otherwise, the 'candidate TWS' was set as the sum of the 'filtered candidate TWS' and 'TWS increment', and steps (2)-(5) were repeated. More details about the forward-modeling method can also be found in [16,31].

The forward-modeling method does not rely on external data. It has been validated in Greenland [31,32], Northwest India [33], West Antarctica [34] and Tonle Sap Basin [16]. To assess its efficiency in the YRB, the CSR RL05 mascon solution and GRACE Tellus monthly mass grids were introduced for comparison. The CSR RL05 mascon solution was purely computed by GRACE data, which is independent of external data [35]. In contrast, the scale factors of the GRACE Tellus monthly mass grids were computed by applying the same filters applied to the GRACE data to a numerical land-hydrology model (NCAR's CLM4) [30,36]. The period of those models covers from January 2003 to March 2016. Note that large increases in TWS variation can be seen in the YRB [37]. However, the linear trends of the TWS variations are mainly sensitive to non-meteorological phenomena or possibly associated with decadal fluctuations in land hydrology [2], which is not the interest in this study. Therefore, the linear trends of the GRACE-derived TWS time series were removed.

\subsubsection{Hydrological Models}

Two kinds of hydrological models were used in this study: PCR-GLOBWB [15-17] and GLDAS [18]. The PCR-GLOBWB model provides monthly TWS estimates as the sum of surface water, soil moisture and groundwater. For clarity, those water components of PCR-GLOBWB are respectively called PCR-GLOBWB (SW), PCR-GLOBWB (SM) and PCR-GLOBWB (GW) in this study. The monthly GLDAS-Noah model was exploited to validate the soil moisture component of PCR-GLOBWB. Note that the GLDAS-Noah model estimates the soil moisture of four layers: 0-10, 10-40, 40-100 and 100-200 cm. In contrast, the PCR-GLOBWB model estimates the soil moisture of two layers: $0-30$ and $30-150 \mathrm{~cm}$. The monthly TWS time series were constructed for the time interval between January 2003 and December 2016. The linear trends were also removed to highlight the seasonal variations for floods and droughts.

\subsubsection{MODIS Data}

MYD09A1 is the eight-day land surface reflectance product from the MODIS Aqua satellite [38], with a spatial resolution of $500 \mathrm{~m}$. It provides seven frequency bands of surface reflectance: 620-670, 841-876, 459-479, 545-565, 1230-1250, 1628-1652 and 2105-2155 nm. The combination of the green band (545-565 nm) and the near infrared (NIR) band (841-876 nm) can efficiently identify the open water bodies in the continent. Therefore, it was exploited to estimate the inundated area variations of Dongting Lake, Poyang Lake and Tai Lake. According to the location of these lakes, the MYD09A1 
tiles of h27v05, h27v06, h28v05 and h28v06 were selected. Note that the quality control flags were used to mask the pixels flagged with cloud cover or to fill values in these tiles. In this study, the normalized difference water index (NDWI) was used [39],

$$
N D W I=(\text { green }-N I R) /(\text { green }+N I R)
$$

The positive NDWI represents an open water body. Since the MYD09A1 product provides the data in the sinusoidal projection (an equal-area map projection), the inundated area of each lake can be estimated by counting the pixels with positive NDWIs. The area of each pixel is $0.25 \mathrm{~km}^{2}$. The monthly time series of inundated areas were then obtained by averaging the eight-day results.

\subsubsection{TRMM Data}

The latest released TRMM (Tropical Rainfall Measuring Mission) data 3B43 Version 7 was used in this study [40]. It provides monthly precipitation estimates from $50^{\circ} \mathrm{S}$ to $50^{\circ} \mathrm{N}$, with a spatial resolution of 0.25 degrees. In addition to estimating the precipitation variations over the YRB, it was also compared with the NCEP/NCAR reanalysis data, which may be helpful to explore the probable inducements of flood and drought events.

\subsubsection{NCEP/NCAR Reanalysis Data}

The NCEP/NCAR reanalysis dataset is a comprehensive dataset with various atmospheric elements [26]. It is derived from the almost perfect database of various observations (ground, ships, aircraft, radiosonde balloon, satellite, etc.). Therefore, the NCEP/NCAR reanalysis dataset has been widely used in meteorology. In this study, for the first time, the NCEP/NCAR vertical velocity data was compared with GRACE in the exploration of climate-induced hydrological activities.

The NCEP/NCAR dataset 'omega.mon.eman.nc' provides the monthly mean vertical velocity at 12 pressure layers. Among these pressure layers, the $500 \mathrm{hPa}$ layer belongs to the middle and upper atmospheric layer, and many weather processes have large or small prints at this level, which can be used to predict future weather changes more accurately. In other words, the $500 \mathrm{hPa}$ layer is one of the most effective layers for diagnosing the deep synoptic system. For these reasons, the vertical velocity at $500 \mathrm{hPa}$ was selected in this study. For clarity, the data was transformed from Pascal/s to $\mathrm{m} / \mathrm{s}$ at first. To obtain the non-seasonal anomalies, the mean values between 1971 and 2000 were then removed. In addition, the NCEP/NCAR dataset 'pr_wtr.mon.mean.nc' was also used. It provides the monthly mean precipitable water for the entire atmospheric column.

\section{Results and Discussion}

\subsection{TWS Variations Over the YRB}

\subsubsection{TWS Derived from Hydrological Models}

The monthly TWS variations derived from two hydrological models are shown in Figure 2. According to Section 2.2.2, the GLDAS model estimates the soil moisture variations between 0 and $200 \mathrm{~cm}$, while the PCR-GLOBWB (SM) model represents the variations between 0 and $150 \mathrm{~cm}$. Although recording soil moisture with a different thickness, as shown in the top panel of Figure 2, the TWSs derived from the GLDAS model present great agreement with those derived from the PCR-GLOBWB (SM) model, with a correlation coefficient of 0.84 . Furthermore, to analyze the relative magnitude of the GLDAS model and the PCR-GLOBWB (SM) model, the Nash-Sutcliffe efficiency (NSE) was also computed [41]. The NSE value is 0.71 , which can be viewed as an acceptable level of performance. The correlation coefficient and NSE value can justify the usage of the PCR-GLOBWB (SM) model to assess the soil moisture variations over the YRB. 


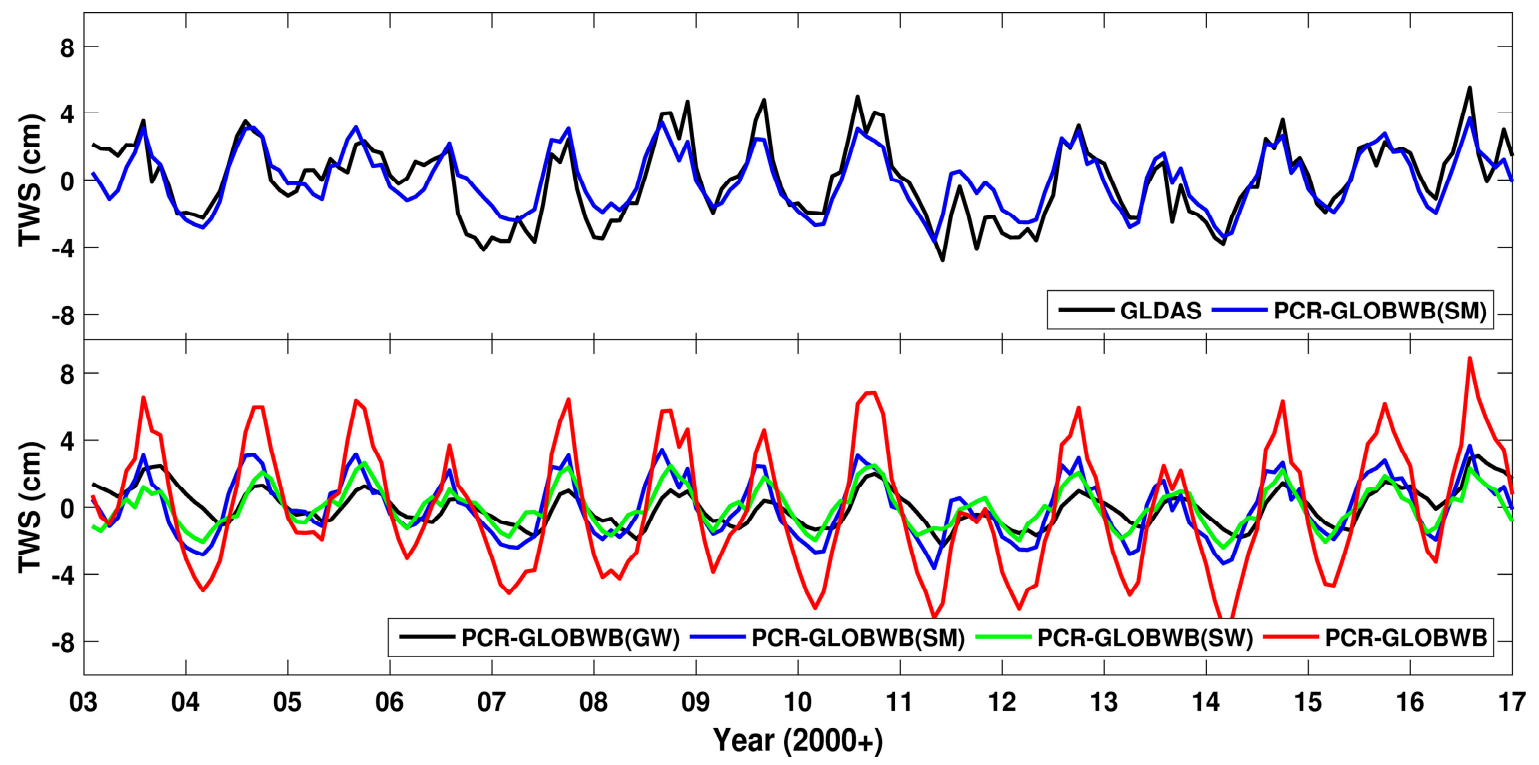

Figure 2. TWS variations of the soil moisture (SM) derived from GLDAS and PCR-GLOBWB are presented in the top panel. TWS variations of groundwater (GW), soil moisture (SM), surface water (SW) and total components derived from PCR-GLOBWB are presented in the bottom panel.

The TWS variations of different water components over the YRB were computed from PCR-GLOBWB. As shown in the bottom panel of Figure 2, there is a very clear seasonal variation for each water component. The water surpluses can be detected in 2010 and 2016, and water deficits can be observed in 2006, 2011 and 2013. The result is inconsistent with the recent findings over the YRB [2,3,42], indicating the flood and drought events in corresponding years. By the way, as shown in the top panel of Figure 2, the differences between the GLDAS and PCR-GLOBWB (SM) can be also seen in 2006 and 2011. This is likely due to the drought events in these years, while more cross-comparisons are needed to verify this assumption in the future.

The PCR-GLOBWB TWSs fluctuated with a range of approximately $\pm 8 \mathrm{~cm}$, while the amplitude of each water component only reached approximately $\pm 4 \mathrm{~cm}$. To assess the role of the individual storages in the TWS variations, the contribution percentage of each water component $(w)$ was computed as [16]

$$
w=\frac{1}{N} \sum_{i=1}^{N} \frac{W_{i}}{T W S_{i}}
$$

where $W_{i}$ and $T W S_{i}$ are the individual water components and TWS variations estimated at month $i$, and $N$ is the total observation period.

The result shows that groundwater contributes $25.0 \%$ to the TWS variations over the YRB, while the soil moisture is the major contributor (49.0\%). The remaining contribution is the surface water, with a percentage of $26.0 \%$. An obvious phase lag can be observed between PCR-GLOBWB (GW) and other water components. The correlation coefficient between PCR-GLOBWB (GW) and PCR-GLOBWB over YRB is 0.81. After moving the TWS of PCR-GLOBWB back for one month, the correlation coefficient reached up to 0.88 . This can be explained as being due to the fact that several weeks are needed to transfer waters from surface and soil to groundwater, and vice versa. In addition, the correlation coefficients for PCR-GLOBWB (SW) and PCR-GLOBWB (SM) are 0.95 and 0.93, respectively. Although with different contribution percentages, such strong correlations indicate the close connection between individual water components and the total TWS over the YRB.

To assess the individual water component in the YRB sub-basins, the contribution percentages and correlation coefficients of each water component were computed (see Table 1). In terms of contribution percentage, groundwater contributes approximately $20.0 \%$ to each sub-basin. It varies considerably for 
surface water, from $7.3 \%$ to $13.5 \%$ in the WYRB (Jinsha River Basin, Minjiang River Basin, Jialin River Basin and Wujiang River Basin), and from 21.9\% to 57.0\% in the EYRB (Hanjiang River Basin, Dongting Lake Basin, Poyang Lake Basin and UMDD). The correlation coefficients between PCR-GLOBWB (SW) and PCR-GLOBWB are all over 0.90, except in the Wujiang River Basin. Note that strong correlations can be found over Dongting Lake Basin and Poyang Lake Basin. It likely justifies the usage of MODIS reflectance data for the cross-comparison of TWS variations over these basins.

Table 1. Contribution percentage (\%) of groundwater (GW), soil moisture (SM) and surface water (SW) to the PCR-GLOBWB TWS variations over each sub-basin of the Yangtze River Basin. The correlation coefficient of each water component with regard to (w.r.t.) PCR-GLOBWB TWS is also listed.

\begin{tabular}{cccccccc}
\hline \multirow{2}{*}{ Location } & \multirow{2}{*}{ Sub-Basin } & \multicolumn{3}{c}{ Contribution Percentage (\%) } & \multicolumn{3}{c}{ Correlation Coefficient } \\
\cline { 3 - 7 } & & GW & SM & SW & GW & SM & SW \\
\hline \multirow{3}{*}{ WYRB } & Jinsha River & 20.4 & 72.3 & 7.3 & 0.64 & 0.98 & 0.91 \\
& Minjiang River & 24.1 & 65.8 & 10.1 & 0.84 & 0.97 & 0.95 \\
& Jialing River & 26.9 & 59.6 & 13.4 & 0.95 & 0.98 & 0.93 \\
& Wujiang River & 22.6 & 63.9 & 13.5 & 0.86 & 0.96 & 0.80 \\
\hline \multirow{3}{*}{ EYRB } & Hanjiang River & 17.9 & 50.6 & 31.5 & 0.88 & 0.97 & 0.96 \\
& Dongting Lake & 15.9 & 58.3 & 25.8 & 0.80 & 0.87 & 0.93 \\
& Poyang Lake & 19.6 & 58.5 & 21.9 & 0.82 & 0.85 & 0.91 \\
& UMDD & 20.2 & 22.8 & 57.0 & 0.76 & 0.73 & 0.92 \\
\hline
\end{tabular}

\subsubsection{TWS Derived from the HUST-Grace2016 Model}

To assess the performance of our HUST-Grace2016 model, the TWS variations over the YRB were computed. They were compared with those computed from CSR RL05, GFZ RL05 and JPL RL05. As shown in the top panel of Figure 3, after applying a Gaussian filter with a $300 \mathrm{~km}$ radius, although not identical, the results derived from HUST-Grace2016 agree extremely well with those derived from the three RL05 models. The correlation coefficients between the HUST-Grace2016 and three RL05 models reached up to $0.95,0.93$ and 0.94 . In contrast, after applying a de-correlation filter (P3M6, see the bottom panel of Figure 3), the correlation coefficients increase to $0.96,0.95$ and 0.95 . Note that the biggest discrepancies can be found in September 2004, in which the ground track is not dense enough $[43,44]$.

To quantify the performance of HUST-Grace2016, Table 2 summarizes the annual amplitude and annual phase of the TWS time series derived from different temporal gravity field models. The results show good consistency, with a discrepancy smaller than $0.1 \mathrm{~cm}$ for annual amplitude and 0.1 month for annual phase. According to the discussions, the performance of HUST-Grace2016 is in great accordance with CSR RL05, GFZ RL05 and JPL RL05 over the YRB. Meanwhile, the ensemble model computed using three RL05 models was also used to compute the TWSs over the YRB. As shown in Table 2, again, good agreement between HUST-Grace2016 and the ensemble model was found with a similar annual amplitude and annual phase. Therefore, our HUST-Grace2016 model was used to quantify the TWS variations over the YRB in this study.

After smoothing by the combined filter (Gauss $300 \mathrm{~km}$ and P3M6 de-correlation), the mean annual amplitude decreased from $3.21 \mathrm{~cm}$ to $2.96 \mathrm{~cm}$ (see Table 2). This indicates that the signal smoothing is accompanied by signal attenuation. This phenomenon is more obvious in Figure $4 \mathrm{a}, \mathrm{b}$ : there are obvious stripe errors after applying a $300 \mathrm{~km}$ Gaussian filter; after smoothing by combined filter, the stripe errors were mitigated, while the temporal signals were also attenuated. To solve this problem, the forward-modeling method was exploited. As shown in Figure 4c, the forward-modeling method weakened the stripe errors, and gathered the temporal signals along the main stream of the Yangtze River. 


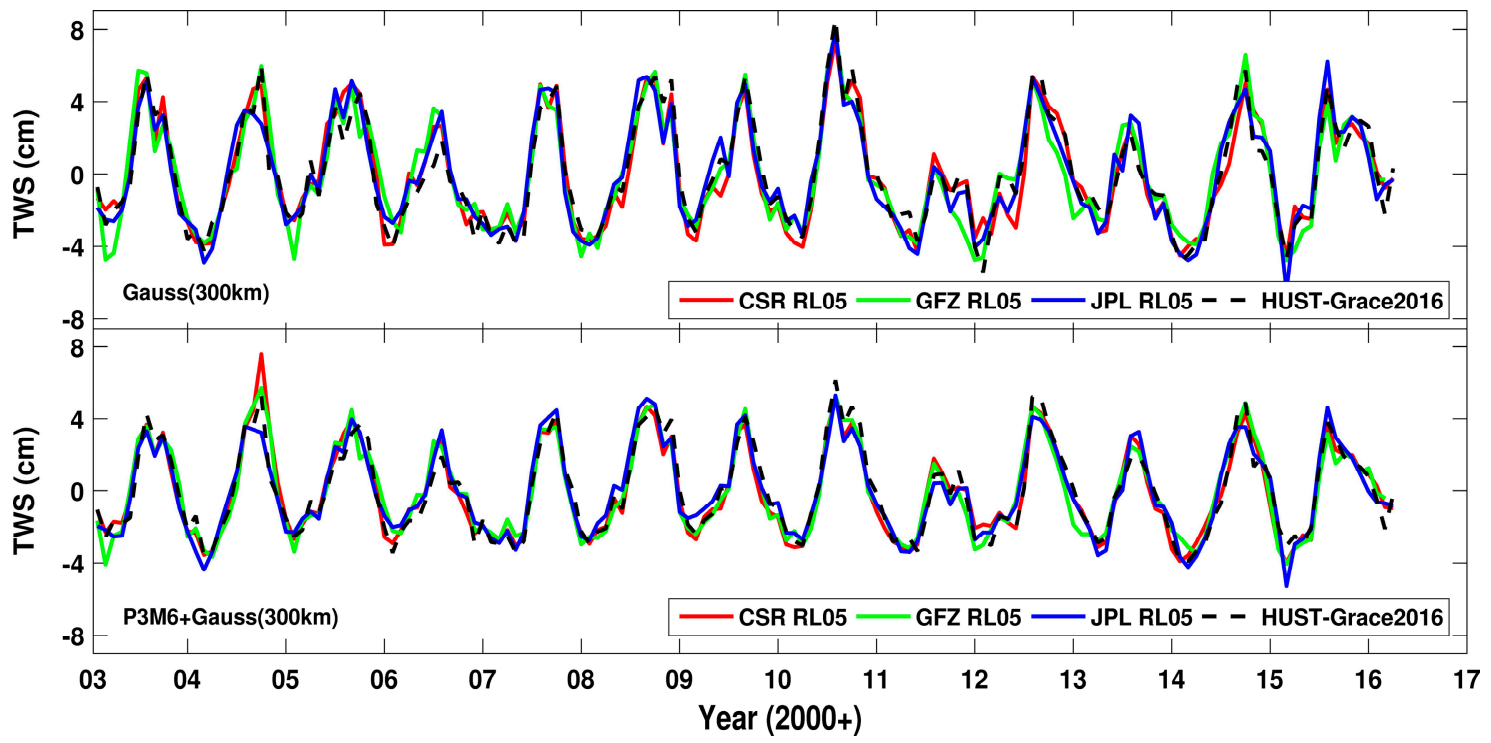

Figure 3. TWS variations over the YRB derived from CSR RL05, GFZ RL05, JPL RL05 and HUST-Grace2016. Top panel shows the TWS after applying $300 \mathrm{~km}$ Gaussian smoothing filter; the bottom panel shows the TWS after applying a $300 \mathrm{~km}$ Gaussian smoothing filter and a P3M6 de-striping filter.

Table 2. Annual amplitude (cm) and phase (month) of TWS variations from different GRACE SHC solutions with different filters.

\begin{tabular}{ccccc}
\hline \multirow{2}{*}{ Models } & \multicolumn{2}{c}{ Gauss (300 km) } & \multicolumn{2}{c}{ P3M6 + Gauss (300 km) } \\
\cline { 2 - 5 } & Annual Amplitude & Annual Phase & Annual Amplitude & Annual Phase \\
\hline HUST-Grace2016 & $3.19 \pm 0.35$ & $4.00 \pm 0.14$ & $2.96 \pm 0.33$ & $4.40 \pm 0.15$ \\
CSR RL05 & $3.19 \pm 0.36$ & $4.02 \pm 0.14$ & $2.96 \pm 0.33$ & $4.41 \pm 0.15$ \\
JPL RL05 & $3.23 \pm 0.36$ & $3.95 \pm 0.13$ & $2.93 \pm 0.33$ & $4.37 \pm 0.15$ \\
GFZ RL05 & $3.22 \pm 0.36$ & $3.97 \pm 0.13$ & $3.00 \pm 0.34$ & $4.33 \pm 0.14$ \\
Ensemble model & $3.21 \pm 0.34$ & $3.99 \pm 0.13$ & $2.96 \pm 0.30$ & $4.39 \pm 0.13$ \\
\hline
\end{tabular}
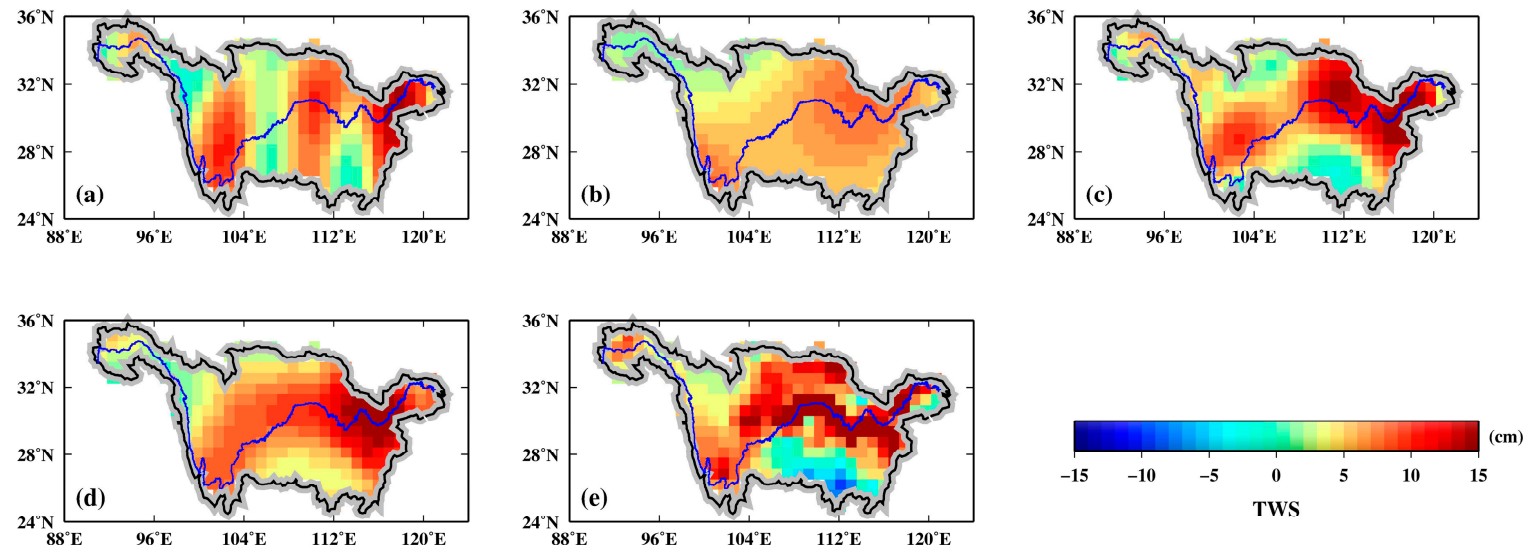

Figure 4. TWS variations derived from HUST-Grace2016 with (a) $300 \mathrm{~km}$ Gaussian filter; (b) $300 \mathrm{~km}$ Gaussian filter and P3M6 de-striping filter; and (c) forward-modeling method. Those derived from (d) CSR RL05 mascon grids and (e) PCR-GLOBWB are also shown.

As the forward-modeling method is independent from the hydrological model or external data, agreement with an independent GRACE solution or a hydrological model can provide some confidence 
in the GRACE TWS estimation. For this reason, the TWSs derived from the CSR RL05 mascon grids and the PCR-GLOBWB model are also presented in Figure 4d,e. Although not identical, the results after forward-modeling matched the PCR-GLOBWB model better than that of the CSR-Mascon. The correlation coefficient with respect to the PCR-GLOBWB model also supported this conclusion, which is 0.58 for HUST-Grace2016 after forward-modeling, and 0.51 for the CSR mascon grids. Furthermore, the correlation coefficient of the TWSs between PCR-GLOBWB and HUST-Grace2016 after applying a $300 \mathrm{~km}$ Gaussian filter (or combined filter) was only 0.33 (or 0.37). This also implicates the outstanding performance of the forward-modeling method over the YRB.

Additionally, comparisons of TWS estimates for the entire time span (between January 2003 and December 2016) were implemented. The top panel of Figure 5 shows the TWS variations derived from different GRACE solutions. Before forward-modeling, the TWSs varied between $\pm 5 \mathrm{~cm}$. After forward-modeling, the leakage errors were mitigated and the temporal signals were more concentrated. As a result, the variation range of corresponding TWSs extended to $\pm 10 \mathrm{~cm}$. Again, although not identical, the TWS variations after forward-modeling present better agreement with CSR mascon grids and the PCR-GLOBWB model. In addition, Table 3 summarizes the results of the TWS variations derived from various GRACE solutions. The values of annual amplitude, annual phase, correlation coefficients and RMS differences with respect to PCR-GLOBWB also demonstrate that, after forward-modeling, the TWS ('HUST After FM' in Table 3) matches best to that of the PCR-GLOBWB model.

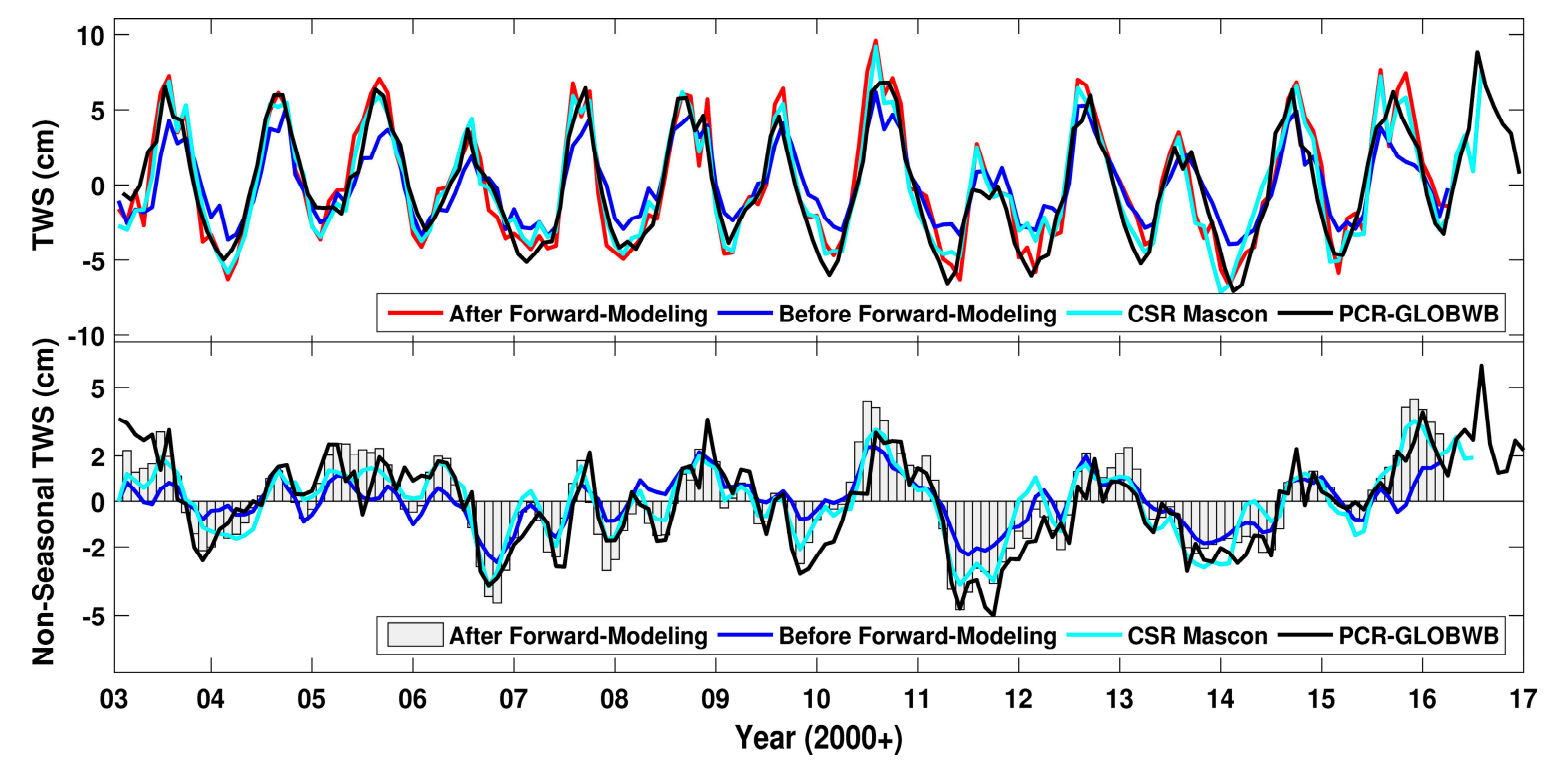

Figure 5. TWS (top) and non-seasonal TWS (bottom) variations over the Yangtze River Basin. The results are derived from the CSR Mascon RL05 grids (cyan line), PCR-GLOBWB model (black line) and HUST-Grace2016 before (blue line) and after forward-modeling (red line for TWS, gray bar for non-seasonal TWS).

The precisely determined TWS estimates were then exploited to assess the hydrological activities over the YRB. Considering only the positive peak of every year between 2003 and 2015, the lowest peak in the GRACE-derived TWS variations was observed in July 2011, quantified as $1.95 \mathrm{~cm}$ equivalent water height $(\mathrm{EWH})$, which is $49 \%$ lower than the mean peak value (computed from the peak values between 2003 and 2015). The second lowest peak value was detected in July 2013: $2.50 \mathrm{~cm} \mathrm{EWH}$ and $35 \%$ lower than the mean peak value. These characteristics related to drought events are also found in the TWS variations derived from the PCR-GLOBWB model. Additionally, in the GRACE TWS estimates, the top two flood events are observed in July of 2010 and 2012. The corresponding peak values are $6.86 \mathrm{~cm}$ and $5.00 \mathrm{~cm}$, which are $74 \%$ and $41 \%$ higher than the mean peak value. These 
peaks are also seen in the PCR-GLOBWB results. As the time span of the GRACE solutions ends in March 2016 in this study, the comparison was only implemented between 2003 and 2015. Note that the largest peak value in the PCR-GLOBWB TWS variations is observed for July 2016: $8.87 \mathrm{~cm} \mathrm{EWH.}$ This peak is $122 \%$ higher than the mean peak value. It suggests the greatest flood events during that year. This conclusion can be also supported by the largest precipitation anomaly observed by TRMM.

Table 3. Annual amplitude (cm) and phase (month) of TWS variations from various GRACE solutions. Correlation coefficients and RMS differences $(\mathrm{cm})$ between HUST-Grace2016 and RL05 models are also provided.

\begin{tabular}{ccccc}
\hline Solutions & $\begin{array}{c}\text { Annual } \\
\text { Amplitude }\end{array}$ & Annual Phase & $\begin{array}{c}\text { Correlation w.r.t. } \\
\text { PCR-GLOBWB }\end{array}$ & $\begin{array}{c}\text { RMS Difference w.r.t. } \\
\text { PCR-GLOBWB }\end{array}$ \\
\hline HUST Before FM & $2.96 \pm 0.33$ & $4.40 \pm 0.15$ & 0.90 & 1.87 \\
HUST After FM & $4.28 \pm 0.48$ & $4.73 \pm 0.14$ & 0.92 & 1.59 \\
CSR Mascon & $4.24 \pm 0.48$ & $4.71 \pm 0.10$ & 0.90 & 1.62 \\
$\begin{array}{c}\text { CSR Tellus grids } \\
\text { (no scale factor) }\end{array}$ & $3.62 \pm 0.40$ & $4.98 \pm 0.12$ & 0.89 & 1.71 \\
$\begin{array}{c}\text { CSR Tellus grids } \\
\text { (with scale factor) }\end{array}$ & $5.98 \pm 0.66$ & $4.34 \pm 0.07$ & 0.92 & 2.41 \\
PCR-GLOBWB & $4.35 \pm 0.48$ & $4.89 \pm 0.10$ & - & - \\
\hline
\end{tabular}

For clarity, the non-seasonal TWS variations are shown in the bottom panel of Figure 5. There is great consistency between the PCR-GLOBWB model and CSR RL05 Mascon as well as HUST-Grace2016 after forward-modeling, with a correlation coefficient of 0.80 and 0.85 , respectively. Additionally, the continuous positive values (longer than six months) can be seen in 2003, 2010, 2012 and 2016. The result demonstrates that flood events occurred in these years. Meanwhile, the continuous negative values indicate that drought events occurred in 2004, 2006, 2011 and 2013.

\subsubsection{Non-Seasonal TWS Variations Over Sub-Basins}

To characterize the flood activity over the YRB, the TWS variations and non-seasonal TWS variations over each sub-basin were computed. In terms of TWS variations, as shown in Table 4, the correlation coefficients indicate good agreement between the PCR-GLOBWB model and HUST-Grace2016 after forward-modeling. After removing the seasonal signals, the GRACE-derived non-seasonal TWS variations still presented strong correlations with those derived from PCR-GLOBWB (all larger than 0.60). The strong correlations provide some confidence in characterizing the flood and drought events over each sub-basin with GRACE-derived non-seasonal TWS variations.

Table 4. Correlation coefficients of TWS variations and non-seasonal TWS variations derived from PCR-GLOBWB w.r.t. HUST-Grace2016 after forward-modeling.

\begin{tabular}{cccc}
\hline Location & Sub-Basins & $\begin{array}{c}\text { Correlations Coefficients } \\
\text { (TWS Variations) }\end{array}$ & $\begin{array}{c}\text { Correlations Coefficients } \\
\text { (Non-Seasonal TWS Variations) }\end{array}$ \\
\hline \multirow{3}{*}{ WYRB } & Jinsha River & 0.83 & 0.70 \\
& Minjiang River & 0.88 & 0.63 \\
& Jialing River & 0.83 & 0.70 \\
& Wujiang River & 0.72 & 0.80 \\
\hline \multirow{2}{*}{ EYRB } & Hanjiang River & 0.84 & 0.82 \\
& Dongting Lake & 0.91 & 0.84 \\
& Poyang Lake & 0.84 & 0.81 \\
& UMDD & 0.83 & 0.79 \\
\hline
\end{tabular}

Figure 6 shows the GRACE-derived non-seasonal TWS variations for the sub-basins. The left four panels present the results for the WYRB, and the right four panels presents those for the EYRB. 
Generally, the amplitude of non-seasonal signals in the EYRB is bigger than those in the WYRB. This is also likely the reason that the correlation coefficients of non-seasonal TWS variations in the EYRB are generally bigger than those in the WYRB (see Table 4).
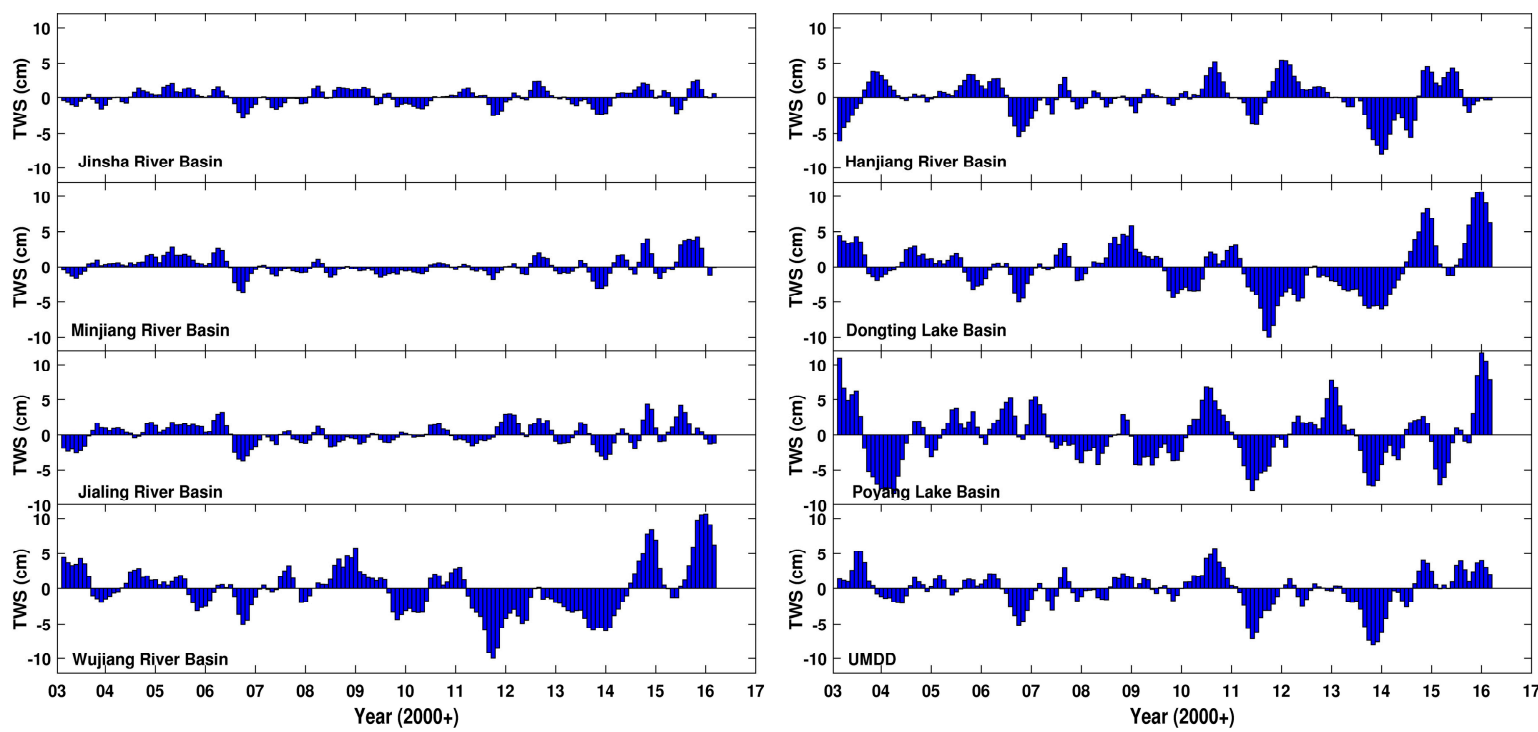

Figure 6. Non-seasonal TWS variations over the sub-basins of the Yangtze River Basin. The results were derived from HUST-Grace2016 after forward-modeling.

As shown in Figure 6, the negative non-seasonal TWS variations in 2011 can be found in almost every sub-basin. It is likely that a drought event occurred over the whole YRB in this year. For clarity, we named this kind of event a 'universal' event. Similarly, these 'universal' drought events can be found in 2006 and 2013. In contrast, the situation in 2004 is special: negative TWSs can be found in four sub-basins (Wujiang River Basin, Dongting Lake Basin, Poyang Lake Basin and UMDD), and obvious positive TWSs were seen in three sub-basins (Minjiang River Basin, Jialing River Basin and Hanjiang River Basin).As the negative signals are stronger than the positive signals, the negative TWSs can be found by averaging the TWSs over the whole YRB (see the bottom panel Figure 5). This indicates a likely 'regional' drought event in 2004.

Likewise, 'universal' flood events can be detected in 2010 and 2012. 'Regional' flood events can be observed in 2003: positive TWSs can be seen in four sub-basins (Wujiang River Basin, Dongting Lake Basin, Poyang Lake Basin and UMDD), and negative TWSs can be observed in four other sub-basins (Jinsha River Basin, Minjiang River Basin, Jialing River Basin and Hanjiang River Basin). Note that in the non-seasonal TWS derived from PCR-GLOBWB, 'universal' flood events can be also detected in 2016 (not shown).

\subsection{MODIS-Derived Inundated Area Variations}

Based on eight-day NDWI values calculated from the MODIS surface reflectance data, the monthly averaged inundated areas of Dongting Lake are shown in Figure 7. Here, only the values in January (representing the dry season) and July (representing the rainy season) between 2008 and 2016 are displayed. In January, the lake is divided into several segments, and the narrow water channel cannot connect these lake segments. In contrast, the lake is always connected in July, and there is a sharp increase in terms of the inundated area over the northeast of Dongting Lake. The results demonstrate dramatic variations between the dry season and rainy season. Additionally, comparing the inundated area in July, the three largest flood extents can be found in 2016, 2010 and 2012, demonstrating that there were flood events in these years. Areas with limited inundation are seen in 2011 and 2013. It is likely that these two years suffered some degree of drought event. 

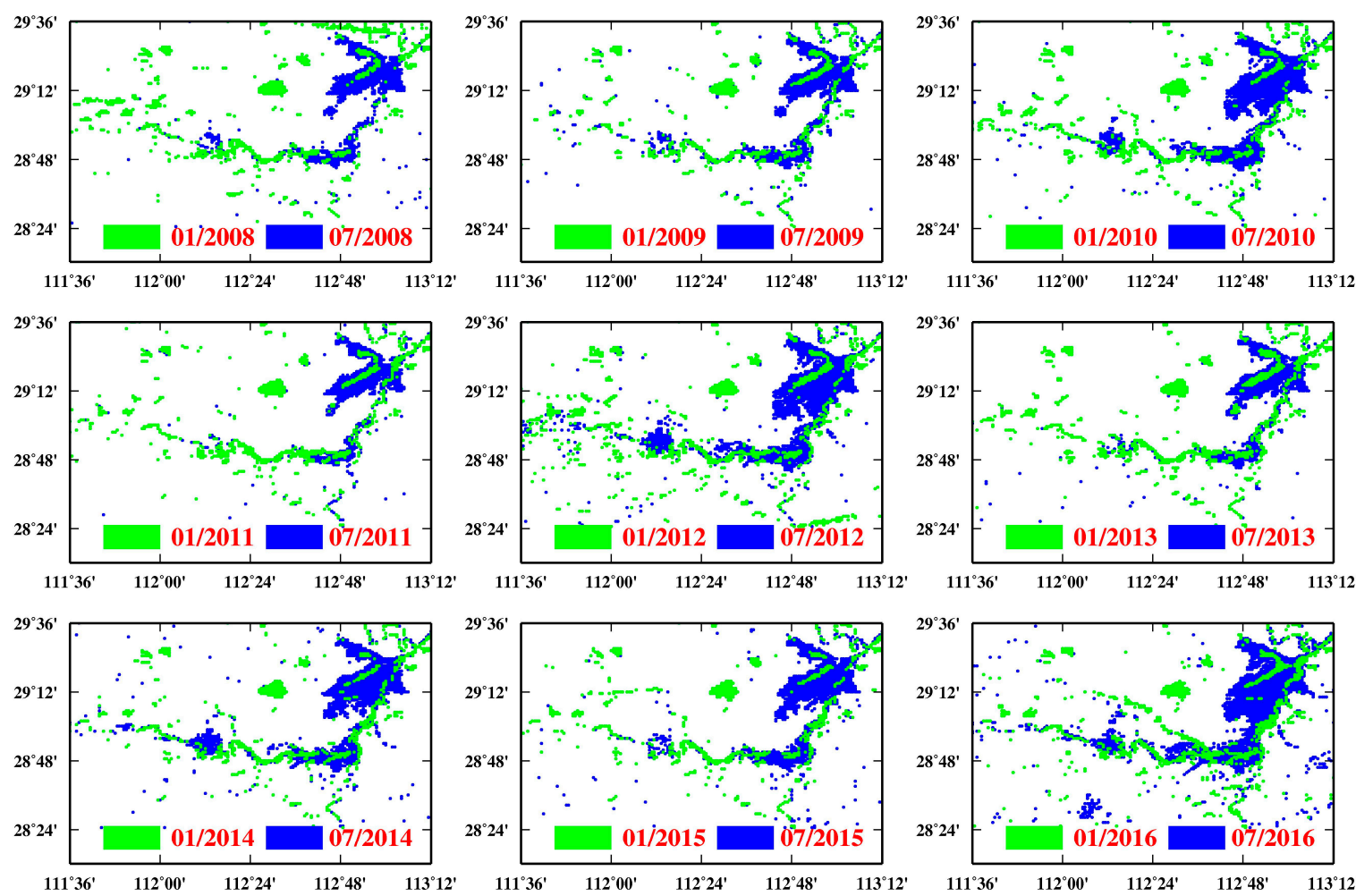

Figure 7. Inundated areas derived from MYD09A1 over Dongting Lake in January (green) and July (blue) during 2008-2016.

To quantify the inundated area variations of Dongting Lake, Figure 8 shows the monthly maximum, minimum and mean values between 2003 and 2016. In the rainy season, the mean inundated areas are larger than $1000 \mathrm{~km}^{2}$ and sometimes reach $2000 \mathrm{~km}^{2}$ or more. In contrast, they are smaller than $1000 \mathrm{~km}^{2}$ in the dry season. Clearly, there is significant variability in both intra-month, intra-season and inter-annual terms.

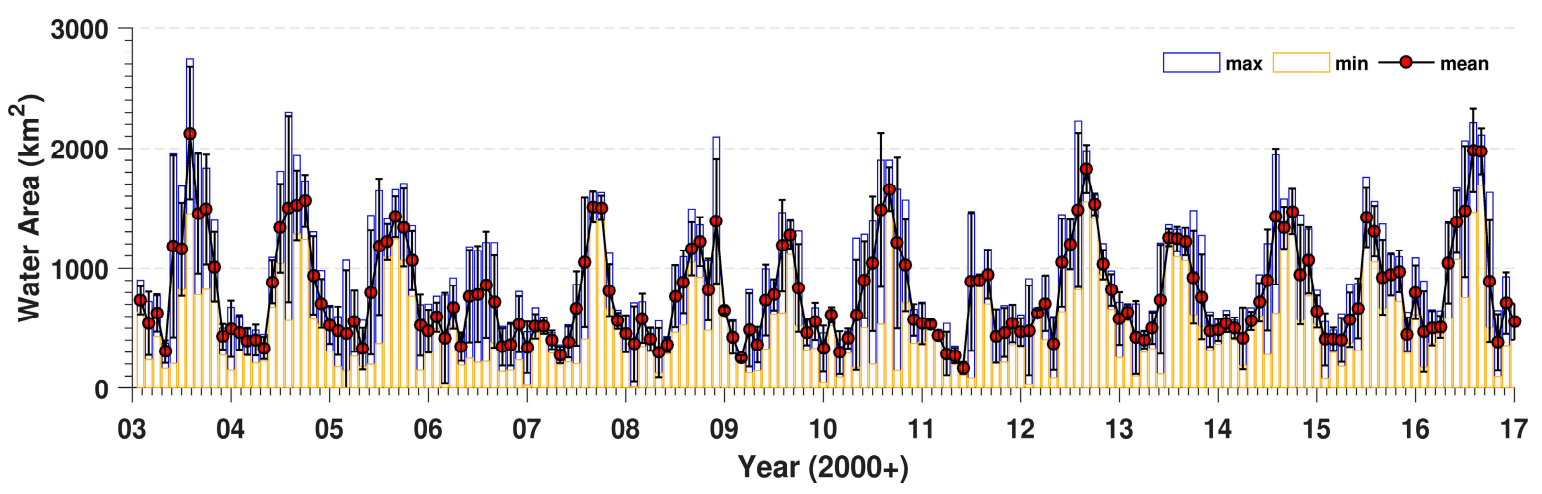

Figure 8. Monthly maximum, minimum and mean inundated area variations between January 2003 and December 2016.

For each climatological month, Table 5 summarizes the occurrence year of the maximum and minimum inundated areas. The monthly maximum in January and February is one to two times smaller than that of June and July. Likewise, a similar situation can be seen in terms of monthly minimum values. In addition, the ratio between the maximum and minimum values varies from 1.99 to 8.18, which also indicates the inter-annual variability for each climatological month. Note that the largest 
ratio (8.18) is seen in June, when the flood event occurred in 2016, while drought events occurred in 2011. Meanwhile, as listed in Table 5, the major occurrence years of the minimum inundated areas are seen in 2006 (four times) and 2011 (three times). It demonstrates that drought and flood events occurred in these years. Likewise, the majority of the maximum inundated areas were observed in 2016 (four times), indicating that Dongting Lake suffered floods in this year.

Table 5. Maximum and minimum inundated area $\left(\mathrm{km}^{2}\right)$ of Dongting Lake between 2003 and 2016. The ratios between maximum and minimum are also listed.

\begin{tabular}{cccccccccccccc}
\hline \multicolumn{2}{c}{ Month } & Jan & Feb & Mar & Apr & May & Jun & Jul & Aug & Sep & Oct & Nov & Dec \\
\hline \multirow{2}{*}{ Max } & Year & 2003 & 2012 & 2012 & 2016 & 2016 & 2016 & 2003 & 2016 & 2004 & 2005 & 2008 & 2015 \\
& Area & 735.3 & 624.0 & 708.8 & 1043.3 & 1385.2 & 1474.8 & 2124.4 & 1975.0 & 1559.3 & 1064.2 & 1392.5 & 799.0 \\
\hline \multirow{2}{*}{ Min } & Year & 2008 & 2009 & 2011 & 2011 & 2011 & 2007 & 2006 & 2006 & 2006 & 2006 & 2003 & 2009 \\
& Area & 370.0 & 249.6 & 288.3 & 272.2 & 169.4 & 664.3 & 860.4 & 720.0 & 344.3 & 365.3 & 429.0 & 331.3 \\
\hline \multicolumn{2}{l}{ Max/Min Ratio } & 1.99 & 2.50 & 2.46 & 3.83 & 8.18 & 2.22 & 2.47 & 2.74 & 4.53 & 2.91 & 3.25 & 2.41 \\
\hline
\end{tabular}

The inundated area variations for Dongting Lake agree well with the GRACE-derived TWS variations for the Dong Lake Basin, with a correlation coefficient of 0.70 (see the top panel of Figure 9). A similarity between the inundated area variations and the TWS variations derived from the PCR-GLOBWB model was also observed, with a correlation coefficient of 0.72. Additionally, the inter-annual variations of Poyang Lake, in terms of inundated areas and TWSs, are also presented in Figure 9. Good agreement was also observed between inundated area variations and TWS variations derived from GRACE and PCR-GLOBWB, with a correlation coefficient of 0.77 and 0.66 , respectively. Comparing the inundated area in July between 2003 and 2016, the two largest values were seen in 2016 $\left(3601.9 \mathrm{~km}^{2}\right)$ and $2010\left(2979.8 \mathrm{~km}^{2}\right)$. These peak values were $57 \%$ and $30 \%$ higher than the mean value in July between 2003 and 2016. Likewise, the top two peak values can be found in TWS variations derived from PCR-GLOBWB: $25.0 \mathrm{~cm}$ in July 2016 and $18.0 \mathrm{~cm}$ in July 2010. Note that GRACE-derived TWS only covers from January 2003 to March 2016. The largest value was observed in 2010: $16.6 \mathrm{~cm}$ in July 2010. Strong correlations were observed between the GRACE-derived TWS variations and the MODIS-derived inundated area variations, this likely implies that the severest flood can also be detected in 2016 by the GRACE-type mission.

Note that the area of Dongting Lake is much smaller than that of the Dongting Lake Basin. Why do the lake-averaged MODIS inundated area variations present strong correlations with the basin-averaged GRACE TWS variations? It can be explained as follows: (1) As shown in Figure 1, Dongting Lake gathers waters from Yuanjiang River and Xiangjiang River, and these two rivers flow through almost the whole basin. For this reason, the GRACE-derived TWS in Dongting Lake likely presents similar characteristics to the average for the whole basin. (2) Meanwhile, as shown in Table 1, a strong correlation (0.93) was found between surface water components and TWS in the Dongting River Basin. (3) Therefore, although only the inundated area of Dongting Lake is used, it still presents a strong correlation with the basin-averaged GRACE TWS estimates. Likewise, the discussion of Dongting Lake is also helpful to explain the strong correlation in Poyang Lake, which gathers waters from Ganjiang River. Additionally, a good counter-example is Tai Lake, which is isolated from all tributaries of the Yangtze River (see Figure 1). In this lake, the MODIS-based estimates of the inundated area present poor correlation (0.10) with the GRACE TWS estimates in the Delta Plain Basin (not shown). In addition, the similar results in terms of altimetry-derived TWS also support our conclusion [45]. 

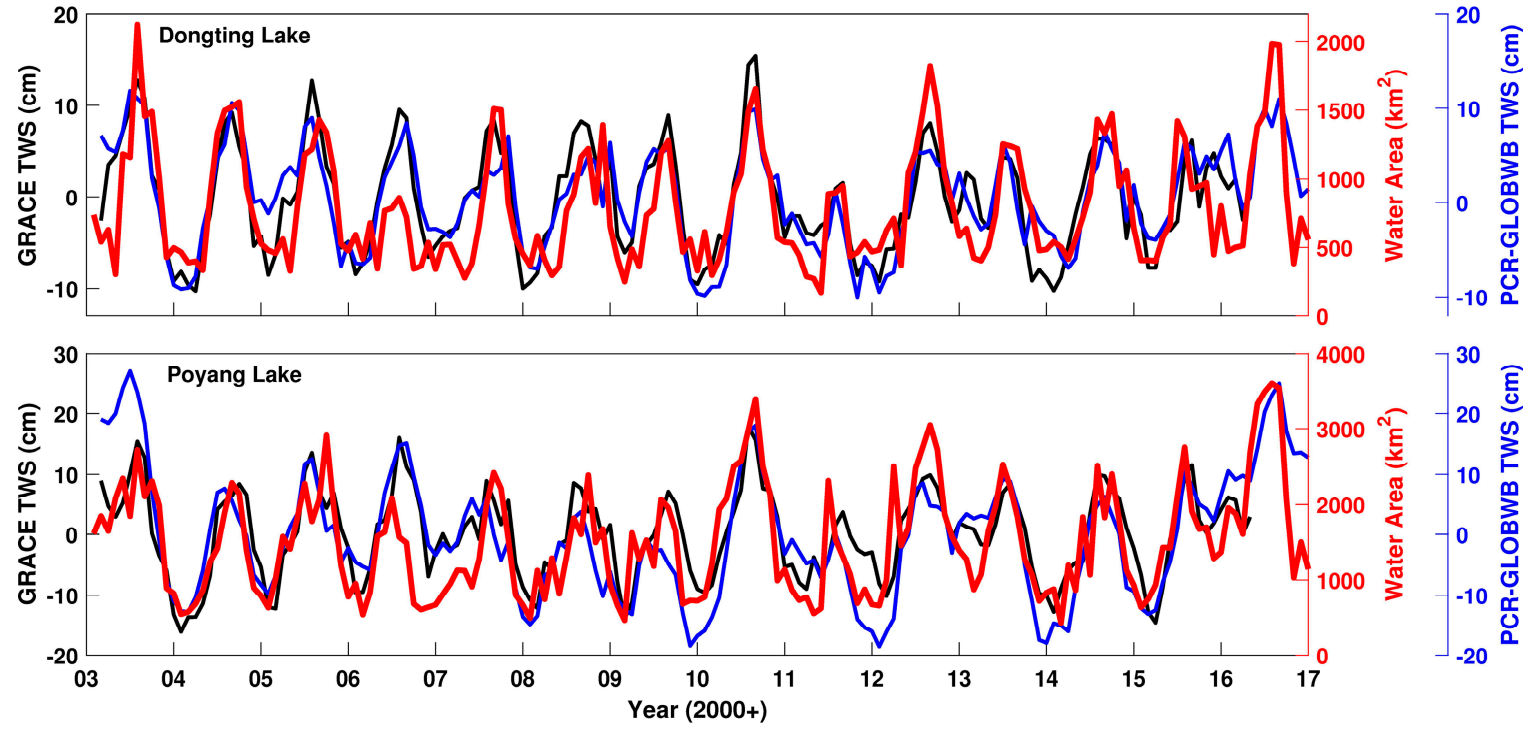

Figure 9. Inundated area variations for Dongting Lake (top) and Poyang Lake (bottom) between January 2003 and December 2016. TWS variations derived from GRACE and PCR-GLOBWB are also provided.

\subsection{NCEP/NCAR Vertical Velocity}

In meteorology, convection primarily refers to atmospheric vertical motion. The NCEP/NCAR vertical velocity data, which quantifies this motion, is always used to analyze the climatological rainfall [46,47]. As discussed in Section 3.1.1, the surface water component, which is sensitive to precipitation, has a strong correlation with PCR-GLOBWB TWS. Meanwhile, GRACE-derived TWS presents a strong correlation with that of the PCR-GLOBWB model. For these reasons, the GRACE-derived TWS was compared with the NCEP/NCAR vertical velocity data, which may improve the understanding of the climate-induced hydrological activities.

As shown in Figure 10, the precipitable water seemingly correlates to the topography: $>50 \mathrm{~kg} / \mathrm{m}^{2}$ of precipitable waters are seen in the YRB, except for the areas with $>2000 \mathrm{~m}$ elevation. Interestingly, regardless of the flood year (2010 and 2012) or the drought year (2011), there is slight difference for the precipitable waters over the YRB. However, the precipitation, which is derived from TRMM data, seems surplus in 2010 or 2012, and deficit in 2011. Likewise, surplus vertical velocities were seen in 2010 and 2012, while deficit vertical velocities were observed in 2011. Note that the majority of the differences in terms of precipitation and vertical velocity were detected in the Dongting Lake Basin and Poyang Lake Basin, where large positive and negative TWS anomalies are also observed (see Figure 6). 

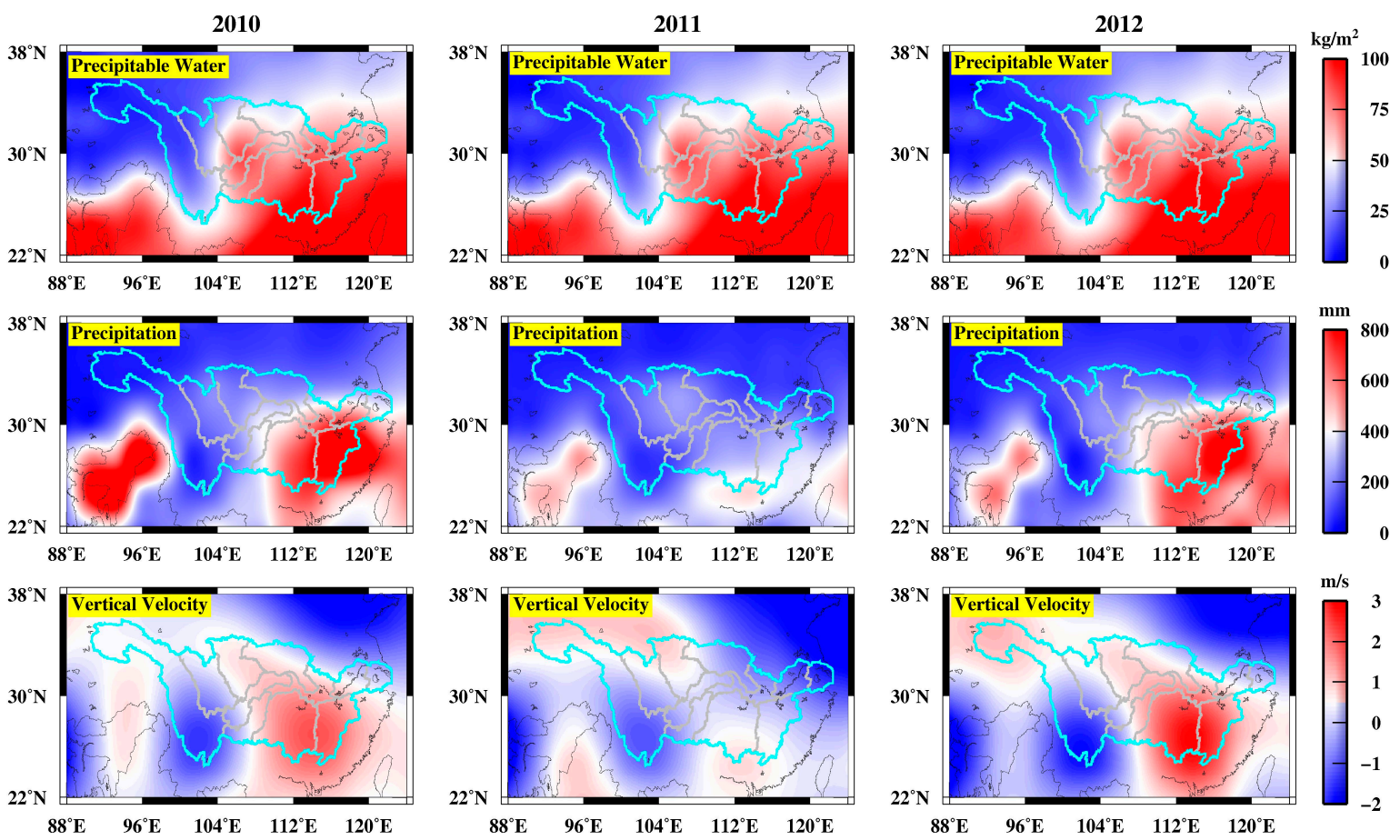

Figure 10. NCEP/NCAR precipitable water $\left(\mathrm{kg} / \mathrm{m}^{2}\right)$, TRMM-derived precipitation $(\mathrm{mm})$ and NCEP/NCAR vertical velocity (m/s) over the Yangtze River Basin in the spring of 2010, 2011 and 2012.

Based on the points discussed above, it is likely that the vertical velocity anomaly is one of the reasons for the hydrological activities over the YRB. To verify this assumption, the monthly non-seasonal GRACE-derived TWS was compared with monthly non-seasonal vertical velocity in the YRB (Figure 11). The correlation coefficient between these two time series is 0.34 . Such a positive correlation is an implication that vertical velocity can be used to analyze the monthly hydrological activities over the YRB. Specifically, positive anomalies for the GRACE-derived TWS and vertical velocity were seen during the 'universal' flood periods (2010, 2012 and 2016). In contrast, negative values for the non-seasonal TWS and non-seasonal vertical velocity were observed during the 'universal' drought events (2006, 2011 and 2013). Here, a brief discussion tries to analyze the relationship between the vertical velocity variations and the GRACE-derived TWS variations as follows: (1) a strong positive vertical velocity represents an upward thermal, and it heats the overlying air, which gradually becomes less dense than the surrounding air; (2) the warmer and less dense water evaporates, and rises into the drier and colder air in the middle atmosphere; (3) the thermal is cooled and water vapor is condensed, forming a small cloud or steam; (4) the cumulated clouds or steam facilitates rainfall; (5) following continuous rainfall, flood events occur, and it can be observed as a positive GRACE-derived TWS anomaly. Likewise, the 'universal' drought events can be explained by the continuous negative non-seasonal vertical velocities. Furthermore, as the precipitation derived from TRMM is commonly used for a better understanding of the processes responsible for the observed TWS variations $[7,16,48,49]$, a cross-comparison was also implemented between GRACE-derived TWS, TRMM-derived precipitation and NCEP/NCAR-derived vertical velocity. As shown in Figure 11, the consistency between the non-seasonal values can also be seen during the 'universal' drought and flood events. Specifically, the correlation coefficients between non-seasonal TWS and non-seasonal precipitation reached up to 0.71 , indicating that TWS variations follow the precipitation variations over the YRB. 


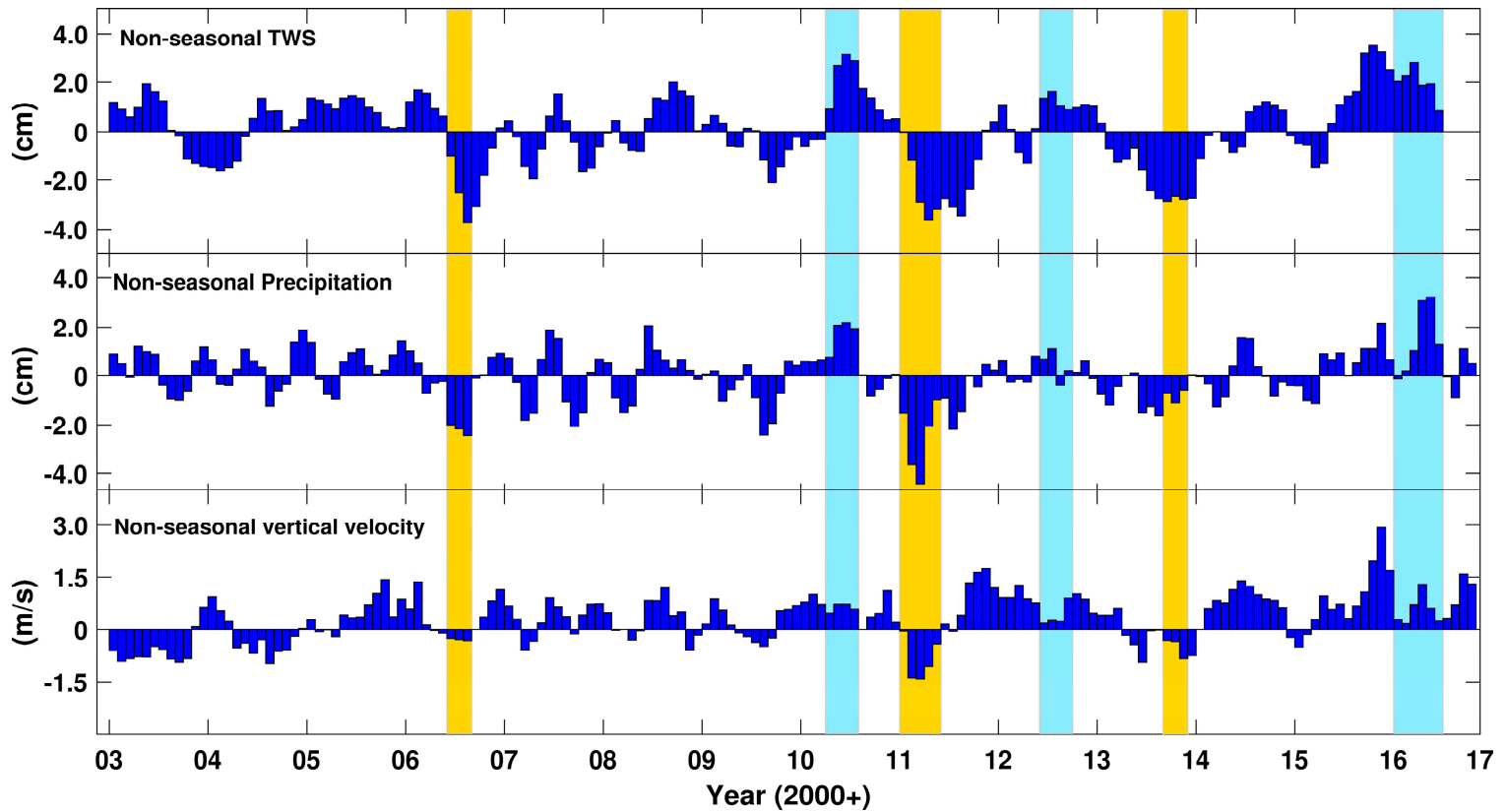

Figure 11. Non-seasonal TWS derived from HUST-Grace2016 after forward-modeling, non-seasonal precipitation derived from TRMM, and non-seasonal vertical velocity over the Yangtze River Basin for the period of January 2003 and December 2016. Yellow shades represent the drought periods, and cyan shades represent flood periods.

However, the opposite results were observed in 2003 and 2004. For instance, the non-seasonal TWS was positive in the rainy season of 2003, while negative vertical velocity is seen during this period. It can be partly explained by the conclusions in Section 3.1.3: compared with other 'universal' flood events over the YRB, the flood that occurred in 2003 was 'regional'. Likewise, the regional drought event in 2004 was also likely the reason for the inconsistent feature between non-seasonal TWS and non-seasonal vertical velocity in that year. Furthermore, excluding the period with 'regional' hydrological activities (i.e., for the period of 2005-2016), the correlation coefficient between non-seasonal TWS and non-seasonal vertical velocity reached up to 0.51 .

\section{Summary and Conclusions}

In this study, the spatio-temporal characteristics of TWS variations over the YRB and its sub-basins were investigated using a new GRACE temporal gravity model, HUST-Grace2016, the PCR-GLOBWB hydrological model, MODIS reflectance data and NCEP/NCAR vertical velocity data.

In terms of TWS, the major focus was on GRACE-based estimates from HUST-Grace2016. After applying spatial filters, the TWS variations derived from HUST-Grace2016 agreed well with those derived from CSR RL05, GFZ RL05 and JPL RL05, as well as their ensemble model. The forward-modeling approach showed great potential in enhancing the quality of the GRACE TWS estimates over the YRB. After applying forward-modeling, the HUST-Grace2016 TWS estimates presented good agreement with CSR mascon grids as well as PCR-GLOBWB estimates. The GRACE TWSs and non-seasonal TWSs were then used to identify the flood events and drought events over the YRB. Additionally, to distinguish these hydrological activities, the non-seasonal TWS estimates over the sub-basins of the YRB were compared. As a result, the 'universal' floods (droughts) were found in 2010, 2012 and 2016 (2006, 2011 and 2013), while a 'regional' flood was observed in 2003 (2004).

The PCR-GLOBWB model covers almost all water components, indicating its potential in validating GRACE results. The agreement with the independent source PCR-GLOBWB model provided some confidence for the GRACE TWS estimation. Additionally, the PCR-GLOBWB model was 
used to estimate the contribution of each water component. As a result, the groundwater, soil moisture and surface water contributed $25.0 \%, 49.0 \%$ and $26.0 \%$ to the TWS variations over the YRB. Note that the situation is different for the WYRB and EYRB, in which the mean contribution percentage of surface water was approximately $11.1 \%$ and $34.1 \%$, respectively.

The MODIS-derived inundated area also indicated its potential in characterizing hydrological activities over the YRB. For instance, the three largest inundated areas of Dongting Lake were found in the flood years (2016, 2010 and 2012), demonstrating that these years suffered some degree of floods. Likewise, the limited inundated areas in July of 2011 and 2013 were an implication of drought events in these years. Additionally, the intra-month and inter-annual inundated area variations of Dongting Lake and Poyang Lake also showed their great potential in validating GRACE TWS estimates. However, Tai Lake was a counter-example, with a correlation coefficient of 0.1 between GRACE TWS estimates and MODIS estimates. It is likely that the usage of the MODIS-derived inundated area for the GRACE TWS validation is limited to the lakes which gather water throughout the river basin.

For the first time, the NCEP/NCAR vertical velocity data was incorporated with GRACE in the exploration of climate-induced hydrological activities. Good agreement was found between the non-seasonal GRACE TWS estimates and the non-seasonal vertical velocities, as well as non-seasonal TRMM-derived precipitation. This was further supported by the consistencies during the 'universal' flood and drought periods. The evidence shown in this study may contribute to the analysis of the mechanism of climate impact on the YRB. Additionally, the methods and datasets used here may be applied to other similar river basins to study the potential characteristics of their hydrological activities.

Acknowledgments: This work was financially supported by the National Natural Science Foundation of China (No. 41704012, 41474019, 41504014, 41504015, 41704011), National 973 Project China (No. 2013CB733302), China Postdoctoral Science Foundation (Grant No. 2016M592337) and the Open Research Fund Program of the State Key Laboratory of Geodesy and Earth's Dynamics (Grant No. SKLGED2017-1-2-E).

Author Contributions: Hao Zhou, Zhicai Luo and Natthachet Tangdamrongsub designed the research; Hao Zhou, Natthachet Tangdamrongsub and Lijie He performed the experiments and analyzed the data; Hao Zhou, Lunche Wang and Lijie He wrote the manuscript; Natthachet Tangdamrongsub, Lunche Wang, Chuang Xu and Qiong Li revised the manuscript.

Conflicts of Interest: The authors declare no conflict of interest.

\section{References}

1. Dai, Z.; Du, J.; Li, J.; Li, W.; Chen, J. Runoff characteristics of the Changjiang River during 2006: Effect of extreme drought and the impounding of the Three Gorges Dam. Geophys. Res. Lett. 2008, 35. [CrossRef]

2. Zhang, Z.Z.; Chao, B.F.; Chen, J.L.; Wilson, C.R. Terrestrial water storage anomalies of Yangtze River Basin droughts observed by GRACE and connections with ENSO. Global Planet. Chang. 2015, 126, 35-45. [CrossRef]

3. Long, D.; Yang, Y.; Wada, Y.; Hong, Y.; Liang, W.; Chen, Y.; Yong, B.; Hu, A.; Wei, J.; Chen, L. Deriving scaling factors using a global hydrological model to restore GRACE total water storage changes for China's Yangtze River Basin. Remote Sens. Environ. 2015, 168, 177-193. [CrossRef]

4. Han, S.C.; Kim, H.; Yeo, I.Y.; Yeh, P.; Oki, T.; Seo, K.W.; Alsdorf, D.; Luthcke, S.B. Dynamics of surface water storage in the Amazon inferred from measurements of inter-satellite distance change. Geophys. Res. Lett. 2009, 36. [CrossRef]

5. Xavier, L.; Becker, M.; Cazenave, A.; Longuevergne, L.; Llovel, W.; Rotunno Filho, O.C. Interannual variability in water storage over 2003-2008 in the Amazon basin from GRACE space gravimetry, in situ river level and precipitation data. Remote Sens. Environ. 2010, 114, 1629-1637. [CrossRef]

6. Awange, J.; Forootan, E.; Kuhn, M.; Kusche, J.; Heck, B. Water storage changes and climate variability within the Nile Basin between 2002 and 2011. Adv. Water Resour. 2014, 73, 1-15. [CrossRef]

7. Yao, C.; Luo, Z.; Wang, H.; Li, Q.; Zhou, H. GRACE-derived terrestrial water storage changes in the inter-basin region and its possible influencing factors: A case study of the Sichuan Basin, China. Remote Sens. 2016, 8, 444. [CrossRef] 
8. Long, D.; Shen, Y.; Sun, A.; Hong, Y.; Longuevergne, L.; Yang, Y.; Li, B.; Chen, L. Drought and flood monitoring for a large karst plateau in Southwest China using extended GRACE data. Remote Sens. Environ. 2015, 155, 145-160. [CrossRef]

9. Bettadpur, S. Gravity Recovery and Climate Experiment UTCSR Level-2 processing standards document for Level-2 product release 0005. In Center for Space Research; University of Texas: Austin, TX, USA, 2012.

10. Dahle, C.; Flechtner, F.; Gruber, C.; König, D.; König, R.; Michalak, G.; Neumayer, K.H. GFZ GRACE level-2 processing standards document for level-2 product release 0005. In Scientific Technical Report-Data; University of Texas: Austin, TX, USA, 2012.

11. Watkins, M.M.; Yuan, D.N. GRACE JPL Level-2 Processing Standards Document for Level-2 Product Release 05. In GRACE 327-744 (v 5.0); Jet Propulsion Laboratory: Pasadena, CA, USA, 2012.

12. Zhou, H.; Luo, Z.; Zhou, Z.; Li, Q.; Zhong, B.; Hsu, H. HUST-Grace2016: A new GRACE monthly gravity field model computed using a modified dynamic approach. J. Geophys. Res. 2017. [CrossRef]

13. Sakumura, C.; Bettadpur, S.; Bruinsma, S. Ensemble prediction and intercomparison analysis of GRACE time-variable gravity field models. Geophys. Res. Lett. 2014, 41, 1389-1397. [CrossRef]

14. Xiao, R.; He, X.; Zhang, Y.; Ferreira, V.G.; Chang, L. Monitoring Groundwater Variations from Satellite Gravimetry and Hydrological Models: A Comparison with in-situ Measurements in the Mid-Atlantic Region of the United States. Remote Sens. 2015, 7, 686-703. [CrossRef]

15. Wada, Y.; Wisser, D.; Bierkens, M.F.P. Global modeling of withdrawal, allocation and consumptive use of surface water and groundwater resources. Earth Syst. Dyn. 2014, 5, 15-40. [CrossRef]

16. Tangdamrongsub, N.; Ditmar, P.G.; Steele-Dunne, S.C.; Gunter, B.C.; Sutanudjaja, E.H. Assessing total water storage and identifying flood events over Tonlé Sap basin in Cambodia using GRACE and MODIS satellite observations combined with hydrological models. Remote Sens. Environ. 2016, 181, 162-173. [CrossRef]

17. Tangdamrongsub, N.; Steele-Dunne, S.C.; Gunter, B.C.; Ditmar, P.G.; Sutanudjaja, E.H.; Sun, Y.; Xia, T.; Wang, Z.J. Improving estimates of water resources in a semi-arid region by assimilating GRACE data into the PCR-GLOBWB hydrological model. Hydrol. Earth Syst. Sci. 2017, 21, 2053-2074. [CrossRef]

18. Rodell, M.; Houser, P.; Jambor, U.E.A.; Gottschalck, J.; Mitchell, K.; Meng, C.J.; Arsenault, K.; Cosgrove, B.; Radakovich, J.; Bosilovich, M. The global land data assimilation system. Bull. Am. Meteorol. Soc. 2004, 85, 381-394. [CrossRef]

19. Feng, L.; Hu, C.; Chen, X.; Cai, X.; Tian, L.; Gan, W. Assessment of inundation changes of Poyang Lake using MODIS observations between 2000 and 2010. Remote Sens. Environ. 2012, 121, 80-92. [CrossRef]

20. Forootan, E.; Awange, J.L.; Kusche, J.; Heck, B.; Eicker, A. Independent patterns of water mass anomalies over Australia from satellite data and models. Remote Sens. Environ. 2012, 124, 427-443. [CrossRef]

21. Forootan, E.; Khandu; Awange, J.L.; Schumacher, M.; Anyah, R.O.; van Dijk, A.I.J.M.; Kusche, J. Quantifying the impacts of ENSO and IOD on rain gauge and remotely sensed precipitation products over Australia. Remote Sens. Environ. 2016, 172, 50-66. [CrossRef]

22. Morishita, Y.; Heki, K. Characteristic precipitation patterns of El Niño/La Niña in time-variable gravity fields by GRACE. Earth Planet. Sci. Lett. 2008, 272, 677-682. [CrossRef]

23. Wouters, B.; Bonin, J.A.; Chambers, D.P.; Riva, R.E.; Sasgen, I.; Wahr, J. GRACE, time-varying gravity, Earth system dynamics and climate change. Rep. Prog. Phys. 2014, 77. [CrossRef] [PubMed]

24. García-García, D.; Ummenhofer, C.C.; Zlotnicki, V. Australian water mass variations from GRACE data linked to Indo-Pacific climate variability. Remote Sens. Environ. 2011, 115, 2175-2183. [CrossRef]

25. Linage, C.D.; Kim, H.; Famiglietti, J.S.; Yu, J.Y. Impact of Pacific and Atlantic sea surface temperatures on interannual and decadal variations of GRACE land water storage in tropical South America. J. Geophys. Res. 2013, 118, 10811-10829. [CrossRef]

26. Kalnay, E.; Kanamitsu, M.; Kistler, R.; Collins, W.; Deaven, D.; Gandin, L.; Iredell, M.; Saha, S.; White, G.; Woollen, J.; et al. The NCEP/NCAR 40-year reanalysis project. Bull. Am. Meteorol. Soc. 1996, 77, 437-470. [CrossRef]

27. Swenson, S.C.; Chambers, D.; Wahr, J. Estimating geocenter variations from a combination of GRACE and ocean model output. J. Geophys. Res. 2008, 113. [CrossRef]

28. Cheng, M.; Tapley, B. Variations in the Earth's oblateness during the past 28 years. J. Geophys. Res. 2004, 109. [CrossRef]

29. Jekeli, C. Alternative methods to smooth the earth's gravity field. In Scientific Report, 327; The Ohio State University: Columbus, OH, USA, 1981. 
30. Swenson, S.C.; Wahr, J. Post-processing removal of correlated errors in GRACE data. Geophys. Res. Lett. 2006, 33. [CrossRef]

31. Chen, J.L.; Wilson, C.R.; Li, J.; Zhang, Z. Reducing leakage error in grace-observed long-term ice mass change: A case study in west Antarctica. J. Geod. 2015, 89, 925-940. [CrossRef]

32. Chen, J.L.; Famiglietti, J.S.; Scanlon, B.; Rodell, M. Groundwater storage changes: Present status from GRACE observations. Surv. Geophys. 2016, 37, 397-417. [CrossRef]

33. Chen, J.L.; Li, J.; Zhang, Z.; Ni, S. Long-term groundwater variations in Northwest India from satellite gravity measurements. Global Planet. Chang. 2014, 116, 130-138. [CrossRef]

34. Chen, J.L.; Wilson, C.R.; Tapley, B.D. Contribution of ice sheet and mountain glacier melt to recent sea level rise. Nat. Geosci. 2013, 6, 549-552. [CrossRef]

35. Save, H.; Bettadpur, S.; Tapley, B.D. High-resolution CSR GRACE RL05 mascons. J. Geophys. Res. 2016, 121, 7547-7569. [CrossRef]

36. Landerer, F.W.; Swenson, S.C. Accuracy of scaled GRACE terrestrial water storage estimates. Water Resour. Res. 2012, 48. [CrossRef]

37. Long, D.; Pan, Y.; Zhou, J.; Chen, Y.; Hou, X.Y.; Hong, Y.; Scanlon, B.R.; Longuevergne, L. Global analysis of spatiotemporal variability in merged total water storage changes using multiple GRACE products and global hydrological models. Remote Sens. Environ. 2017, 192, 198-216. [CrossRef]

38. Vermote, E.F.; Kotchenova, S.Y.; Ray, J.P. MODIS Surface Reflectance User's Guide Version 1.3. 2011. Available online: Http:/ / modis-sr.ltdri.org/guide/MOD09_UserGuide_v1_3.pdf (accessed on 30 June 2017).

39. McFeeters, S.K. The use of the normalized difference water index (NDWI) in the delineation of open water features. Int. J. Remote Sens. 1996, 17, 1425-1432. [CrossRef]

40. Huffman, G.J.; Bolvin, D.T. TRMM and Other Data Precipitation Data Set Documentation. 2017. Available online: Https:// pmm.nasa.gov/sites/default/files/document_files/3B42_3B43_doc_V7_4_19_ 17.pdf (accessed on 30 June 2017).

41. Moriasi, D.N.; Arnold, J.G.; Van Liew, M.W.; Bingner, R.L.; Harmel, R.D.; Veith, T.L. Model evaluation guidelines for systematic quantification of accuracy in watershed simulations. Trans. ASABE 2007, 50, 885-900. [CrossRef]

42. Wang, J.; Sheng, Y.; Wada, Y. Little impact of the Three Gorges Dam on recent decadal lake decline across China's Yangtze Plain. Water Resour. Res. 2017, 53, 3854-3877. [CrossRef]

43. Klokočník, J.; Gooding, R.H.; Wagner, C.A.; Kostelecký, J.; Bezděk, A. The Use of Resonant Orbits in Satellite Geodesy: A Review. Surv. Geophys. 2013, 34, 43-72. [CrossRef]

44. Klokočník, J.; Wagner, C.A.; Kostelecký, J.; Bezděk, A.; Novak, P.; McAdoo, D. Variations in the accuracy of gravity recovery due to ground track variability: GRACE, CHAMP, and GOCE. J. Geod. 2008, 82, 917-927. [CrossRef]

45. Jiang, Q.; Ferreira, V.G.; Chen, J. Monitoring groundwater changes in the Yangtze River basin using satellite and model data. Arab J. Geosci. 2016, 9, 500-506. [CrossRef]

46. Back, L.E.; Bretherton, C.S. A simple model of climatological rainfall and vertical motion patterns over the tropical oceans. J. Clim. 2009, 22, 6477-6497. [CrossRef]

47. Stepanyuk, O.; Räisänen, J.; Sinclair, V.A.; Järvinen, H. Factors affecting atmospheric vertical motions as analyzed with a generalized omega equation and the OpenIFS model. Tellus A 2017, 69. [CrossRef]

48. Andam-Akorful, S.A.; Ferreira, V.G.; Awange, J.L.; Forootan, E.; He, X.F. Multi-model and multi-sensor estimations of evapotranspiration over the Volta Basin, West Africa. Int. J. Climatol. 2015, 35, 3132-3145. [CrossRef]

49. Sun, T.; Ferreira, V.; He, X.; Andam-Akorful, S. Water Availability of São Francisco River Basin Based on a Space-Borne Geodetic Sensor. Water 2016, 8, 213. [CrossRef]

(C) 2017 by the authors. Licensee MDPI, Basel, Switzerland. This article is an open access article distributed under the terms and conditions of the Creative Commons Attribution (CC BY) license (http:/ / creativecommons.org/licenses/by/4.0/). 